\title{
Correlation of Early Total Leucocyte Count and Red Cell Distribution Width with Outcome in Trauma
}

\author{
Bhavana Chowdary Madineni ${ }^{1}$, Sreeramulu Patrapalli Nadipanna ${ }^{2}$, Krishna Prasad Kamisetty ${ }^{3}$ \\ 1, 2,3 Department of General Surgery, R.L. Jalappa Hospital, SDUAHER, Kolar, Karnataka, India.
}

\section{ABSTRACT}

\section{BACKGROUND}

Trauma is the leading cause of morbidity and mortality in young adults. Risk stratification in these patients remains challenging even today. There is a need for a readily available simple prognostic method to categorise these patients and predict the morbidity. We intend to measure and correlate red cell distribution width and total leucocyte count in patients presenting with trauma, within 24 hours of injury, with the outcome.

\section{METHODS}

We included 52 haemodynamically stable, previously healthy, trauma patients who were admitted from November 2019 to April 2020, who did not require emergency surgery and analysed them prospectively. Complete blood picture obtained within 24 hours of injury was analysed in terms of correlation with outcome. The outcome was measured in terms of length of hospital stay. Correlations were performed with the Pearson correlation coefficient.

\section{RESULTS}

There was a statistically significant correlation between total leucocyte count (TLC) and length of hospital stay $(\mathrm{P}<0.001)$. The positive correlation found between red cell distribution width (RDW) and length of hospital stay was not statistically significant. The analysis showed that high leucocyte count and red cell distribution width done within 24 hours of injury, increased patients' stay in the hospital.

\section{CONCLUSIONS}

TLC and RDW can be used as readily available and simple markers, as an adjunct in early prediction of higher morbidity in patients presenting with trauma.

\section{KEY WORDS}

Injuries, Polytrauma, Blood Cell Count, Leucocytosis, Red Cell Indices
Corresponding Author: Dr. Bhavana Chowdary Madineni, SDUMC, Tamaka, Kolar - 563101,

Karnataka, India.

E-mail: bhavanachowdarymadineni@gmail.com

DOI: $10.14260 /$ jemds/2021/264

How to Cite This Article:

Madineni BC, Nadipanna SP, Kamisetty KP. Correlation of early total leucocyte count and red cell distribution width with outcome in trauma. J Evolution Med Dent Sci 2021;10(17):1241-1245, DOI: $10.14260 /$ jemds/2021/264

Submission 05-12-2020,

Peer Review 26-02-2021, Acceptance 04-03-2021,

Published 26-04-2021.

Copyright (C) 2021 Bhavana Chowdary Madineni et al. This is an open access article distributed under Creative Commons Attribution License [Attribution 4.0 International (CC BY 4.0)] 


\section{BACKGROUND}

Trauma is any physical injury caused by a sudden or brief encounter of body with various levels of energy. The word 'trauma' comes from a Greek word 'traûma' which means 'wound'. The most common cause of trauma is road traffic accidents. Trauma is the leading cause of morbidity and mortality in children and young adults. Worldwide, it accounts for the death of approximately 1.35 million people each year. The morbidity caused by trauma is also tremendous, leading to non-fatal injuries affecting the quality of life of approximately 20 - 30 million people around the world each year. Apart from this, the financial burden caused by trauma is alarming, accounting to $3 \%$ of the countries' annual gross domestic product. ${ }^{1}$ In India, during 2019, a total of 4,37,396 cases of 'road accidents' were reported which rendered $4,39,262$ persons injured and 1,54,732 deaths as per national crime records bureau (NCRB). ${ }^{2}$

Trauma can lead to morbidity, increased hospital stays, increased expenditure and sometimes death. There are various scoring systems to predict mortality in patients with severe traumatic injuries. But there is not much progress in haemodynamically stable patients with non-fatal injuries or those in whom surgical intervention is not involved. This group of trauma victims were not given attention by researchers to analyse their outcomes. There is a need for a marker to predict the outcome of such trauma victims early in the course. Despite medical advances, the task of risk stratification in patients with trauma remains challenging. Numerous exhaustive scoring systems and complex serum markers exist to assess the severity of trauma. Nevertheless, putting them in practice is often difficult in emergent situations due to their complexity. Therefore, there is a need for a readily available simple method to categorise these patients.

Trauma being a stress on the human body, shows response similar to that of any other acute insult the inflammation sets in as a part of the stress response and acute-phase reaction. Total leucocyte count and Red cell distribution width are the general inflammatory markers which are easily available and simple to obtain. These markers are of lesser cost and available even in the lowest level of health care centres, unlike certain markers like lactate and base deficit. This made us hypothesize that total leucocyte count and red cell distribution width obtained within 24 hours of injury might predict the outcome in the form of the length of hospital stay, in patients with nonfatal injuries. Studies have shown that total leucocyte count (TLC) and red cell distribution width (RDW) correlate with the severity of injury and independently predict mortality in trauma victims. ${ }^{3-6}$ No study assessed using these simple markers to predict the length of hospital stay.

The purpose of the study was to correlate red cell distribution width and total leucocyte count with the outcome in terms of length of hospital stay, in patients presenting with trauma.

\section{METHODS}

We conducted a prospective observational study among 52 patients from November 2019 to April 2020 and selected according to inclusion and exclusion criteria. Sample size was calculated using standard deviation of 8.47 variance estimate on WBC counts and $99 \%$ confidence interval, $80 \%$ power and absolute precession of 3 thousand $/ \mathrm{mm}^{3}$ The formula used was

$$
\mathrm{n}=\frac{z_{1-\alpha / 2}^{2} \sigma^{2}}{d^{2}}
$$

We analysed the subjects in the direction of testing our hypothesis in R.L. Jalappa Hospital and Research Centre, affiliated to Sri Devaraj Urs Academy of Health Education and Research, a level 1 trauma centre located on a National highway Kolar, Karnataka.

\section{Inclusion Criteria}

Trauma patients admitted in R.L. Jalappa Hospital and Research Centre during the study period and who were hemodynamically stable and deemed previously healthy.

\section{Exclusion Criteria}

Patients who required emergency surgery or having comorbidities were excluded. We excluded the patients with comorbid conditions like diabetes mellitus, hypertension, and immunocompromised states as these might affect the levels of markers in our study, RDW and TLC. Studies showed an increase in RDW in chronic disorders and independently predict mortality in these patients. ${ }^{7,8}$ Hence, we excluded patients with comorbidities. The decision to exclude patients requiring emergency surgery was made because the markers used in the study would not help predict hospital stay, as it was mostly dependent on the underlying surgical pathology, the timing and nature of surgery. Most of the patients in whom the decision of emergency surgical intervention was made, were haemodynamically unstable.

A detailed clinical history, including the comorbid conditions and pre-trauma health status, was recorded. Complete blood picture done within 24 hours of injury was obtained. The outcome was measured in terms of length of hospital stay in the study subjects.

Data collected include patients demographic data, age, sex, mode of trauma, time of trauma, injuries sustained, complete blood picture (done within 24 hours of trauma), and hospital stay duration. Previous history of comorbid conditions including diabetes mellitus, hypertension, chronic obstructive pulmonary disease (COPD) bronchial asthma, chronic kidney disease, immune compromised state and other major medical illnesses. Since our hospital serves as a trauma centre within 30 kilometres radius, most of the trauma patients were brought to our hospital immediately. We obtained the complete blood picture from these patients on arrival, which helped us to gather the information of early total leucocyte count and red cell distribution width within 24 hours of injury.

The correlation between TLC values and RDW \% with the length of hospital stay of the study subjects were analysed separately using scatter plot graphs. Also, the subjects were divided into two groups, according to the leucocyte count and RDW \%. TLC $>13$ thousand $/ \mathrm{mm}^{3}$ and RDW $>14 \%$ was taken 
as the cut-off. The length of hospital stay was compared in both the groups.

\section{Ethics Approval and Consent to Participate}

Ethical Clearance was taken from the Institutional Ethics Committee, Sri Devaraj Urs Medical College. Consent was obtained from all the subjects involved in the study for publication of their data.

\section{Statistical Analysis}

Data was entered into Microsoft Excel datasheet and was analysed using SPSS 22 version software. Categorical data was represented in the form of frequencies and proportions. Continuous data was represented as mean and standard deviation. We used the Student t test of significance to identify the mean difference between two quantitative variables. Correlations were performed with the Pearson correlation coefficient. P-value (probability that the result is accurate) of $<0.05$ was considered as statistically significant after assuming all the rules of statistical tests. Statistical software: MS Excel, SPSS version 22 (IBM SPSS Statistics, Somers NY, USA) was used to analyse data.

\section{RESULTS}

Out of the total 52 patients analysed, $88.5 \%$ were males and $11.5 \%$ were females. Mode of injury in the study population included road traffic accidents (RTA) and injuries following alleged assaults. $80.8 \%$ of the subjects had RTA, making it the most common cause of trauma in our study population. $19.2 \%$ of the subjects sustained injuries following alleged assaults.

Table 1 showcases the distribution of the study population across various age groups. Majority of the subjects $(32.7 \%)$ were in 21 - 30 years age group. Whereas $23.1 \%$ of the subjects were aged between 41 - 50 years, $21.2 \%$ of the subjects were in 31 - 40 years age group, $11.5 \%$ of the subjects in 51 - 60 years age group, $5.8 \%$ of subjects each in $<20$ years age group and $61-70$ years age group.

\begin{tabular}{|ccc|}
\hline Age Group & Number (N) & Percentage (\%) \\
\hline$<20$ yrs. & 3 & 5.8 \\
$21-30$ yrs. & 17 & 32.7 \\
$31-40$ yrs. & 11 & 21.2 \\
$41-50$ yrs. & 12 & 23.1 \\
$51-60$ yrs. & 6 & 11.5 \\
$61-70$ yrs. & 3 & 5.8 \\
\hline Total & 52 & 100 \\
\hline Table 1. Distribution of Study Subjects across Various Age Groups \\
\hline
\end{tabular}

The mean length of hospital stay in the study subjects was $11 \pm 6$ days. The study subjects were divided based on the TLC and RDW values. The length of hospital stay was compared in both the groups. TLC $>13$ thousand $/ \mathrm{mm}^{3}$ and RDW $>14 \%$ was taken as the cut-off. The difference in length of the hospital stay in both the groups is represented in Table 2. The mean length of the hospital stay in patients with high TLC was significantly higher than in those with low TLC, i.e., $14 \pm 6$ days vs $9 \pm 5$ days $(P<0.001)$. The mean length of hospital stay was slightly higher in patients with high RDW \% than those with low RDW \%, but is not significant statistically, i.e., $12 \pm 5$ days vs $11 \pm 6$ days $(\mathrm{P}=0.755)$.

\begin{tabular}{|c|c|c|c|c|}
\hline \multirow{2}{*}{\multicolumn{2}{|c|}{ Parameters }} & \multicolumn{2}{|c|}{ Length of Hospital Stay } & \multirow{2}{*}{ P-Value } \\
\hline & & Mean & Standard Deviation & \\
\hline \multirow{2}{*}{ TLC } & $<13,000$ & 9 & 5 & \multirow{2}{*}{$<0.001$} \\
\hline & $\geq 13,000$ & 14 & 6 & \\
\hline \multirow{2}{*}{ RDW } & $<14$ & 11 & 6 & \multirow{2}{*}{0.755} \\
\hline & $>14$ & 12 & 5 & \\
\hline \multicolumn{5}{|c|}{$\begin{array}{c}\text { Table 2. Mean Length of Hospital Stay in Study Subjects } \\
\text { Based on TLC and RDW }\end{array}$} \\
\hline
\end{tabular}

Descriptive statistics like mean and standard deviation of the parameters i.e., total leucocyte count, red cell distribution width and haemoglobin, which were measured at arrival within 24 hours of injury are represented in Table 3, along with the correlation of the same with the length of the patient's stay in hospital.

Correlation of length of hospital stay was analysed for TLC, RDW and haemoglobin values in all the study subjects, which is shown in Table 3. TLC had a positive correlation with the length of hospital stay, which was statistically significant, and RDW had a positive correlation with the length of hospital stay, which was not statistically significant.

Correlation was analysed using scatter plots. Figure 1 represents the scatter plot of length of hospital stay with TLC, whereas Figure 2 shows the scatter plot of RDW \% against length of hospital stay in the study population.

\begin{tabular}{|c|c|c|c|c|}
\hline Parameters & Mean & $\begin{array}{l}\text { Standard } \\
\text { Deviation }\end{array}$ & \multicolumn{2}{|c|}{ Length of Hospital Stay } \\
\hline \multirow{2}{*}{ TLC } & \multirow{2}{*}{12.9623} & \multirow[t]{2}{*}{5.6121} & $\begin{array}{l}\text { Pearson } \\
\text { correlation }\end{array}$ & 0.441 \\
\hline & & & P-value & $<0.001$ \\
\hline \multirow{2}{*}{ RDW } & \multirow{2}{*}{13.3} & \multirow[t]{2}{*}{1.2} & $\begin{array}{l}\text { Pearson } \\
\text { correlation }\end{array}$ & 0.070 \\
\hline & & & P-value & 0.621 \\
\hline \multirow[t]{2}{*}{ Haemoglobin } & \multirow{2}{*}{13.0250} & \multirow[t]{2}{*}{2.3911} & $\begin{array}{l}\text { Pearson } \\
\text { correlation }\end{array}$ & -0.033 \\
\hline & & & P-value & .832 \\
\hline $\begin{array}{r}\text { Table } 3 . \\
\text { Ho }\end{array}$ & $\begin{array}{l}\text { scriptive } \\
\text { ital Stay }\end{array}$ & $\begin{array}{l}\text { tistics and } \\
T L C, R D W\end{array}$ & $\begin{array}{l}\text { relation of } \\
\text { Haemoglo }\end{array}$ & th of \\
\hline
\end{tabular}

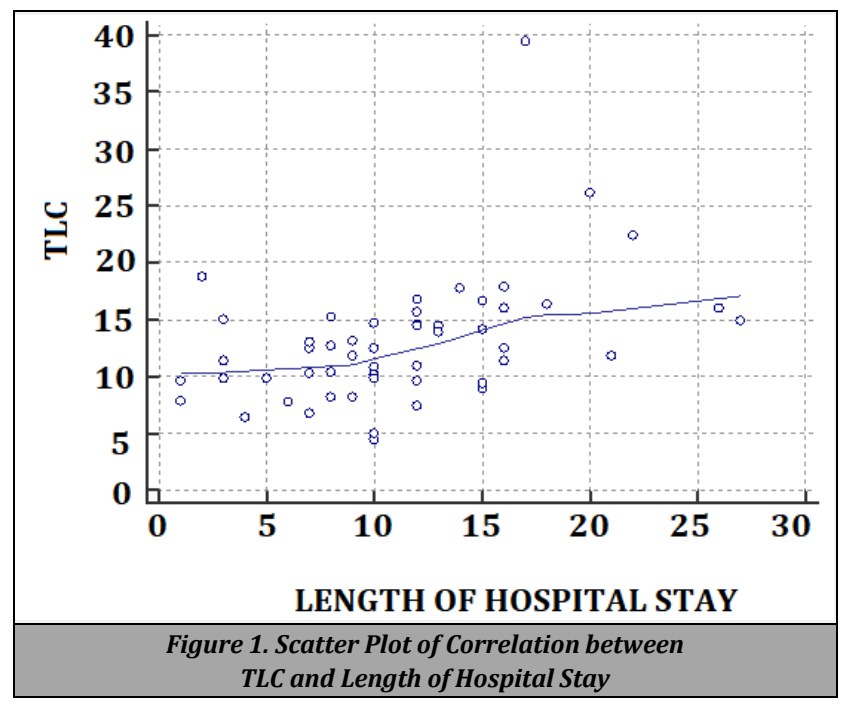

There was a positive correlation of TLC with length of hospital stay in the study population, which was significant statistically. There was a positive correlation but not 
significant statistically, between RDW \% and Length of hospital stay in the study population.

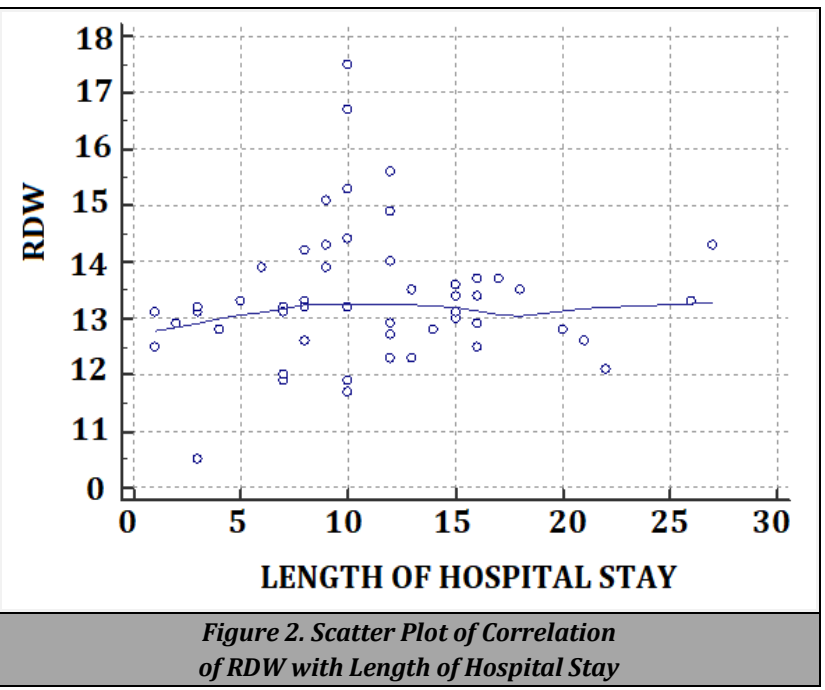

\section{DISCUSSION}

The effect of trauma on victims can be varied, from superficial injuries not requiring admission to, in some cases, causing immediate death. The outcome of trauma patients in severe injuries like those requiring emergency surgeries is guarded and can be assessed using various scoring systems and other modalities. These indices prove to be limitedly useful in assessing the length of hospital stay in patients with non - fatal injuries.

Various factors affect the outcome in a trauma patient including severity of trauma, patient factors like age, comorbid conditions and the timing of treatment or intervention. Complex scoring systems evolved including these factors. The complex scoring systems are time and resource consuming and are cumbersome. Simple markers and scoring systems although not perfect, help in resource limited settings and also in taking emergent decisions.

The effect of trauma in patients who sustained injuries of non - fatal nature and lesser severity like soft tissue injuries, mild head injuries or superficial stab injuries which do not require emergency surgical exploration were poorly studied. In fact, this group of trauma patients remain uncared, due to the subtility of their injuries. However, surprisingly the level of anxiousness was high in this group of patients and their families regarding the outcome. To attend these patients, we needed a simple marker to predict the outcome early in the course.

Like the shock index and revised trauma score, numerous indices evolved to predict the severity and further course through the hospital in trauma victims. Many of the trauma indices and scoring systems failed to predict the morbidity, inhospital stay and effect of trauma in such group of trauma victims. Complex scoring systems like Triss, Ascot, Iciss, Sofa, Tash which evolved are optimal in predicting all parameters but at the cost of practicality. They are cumbersome in practice. Hence, there is a need for simple markers predicting the hospital stay in trauma victims with non-fatal injuries, especially in resource poor settings.
Acute-phase response is an inevitable event following trauma, which is mediated by increased levels of inflammatory cytokines, catecholamines and corticosteroids. TLC and RDW $\%$ are general reflectors of inflammation in the body. These are simple and inexpensive and easily available, unlike certain other markers like lactate, $\mathrm{C}$-reactive protein and base deficit.

Trauma, being a stress factor, post-traumatic leucocytosis is a well-observed phenomenon. However, the mechanisms are poorly understood. The leucocytosis is mostly constituted by neutrophils. There are various mechanisms described including the release of storage pool of neutrophils from the bone marrow, demargination of leucocytes. The biphasic leucocytosis is transient, which disappears once the causative stress factor is eliminated. ${ }^{9}$

The association of high early TLC and severity of the head injury is well observed.10 Historically, clinicians tend to be more alert and assume underlying pathology in patients with high admission leucocyte counts. Various studies described controversial results on the association of early TLC with the severity of the trauma, which includes abdominal trauma, soft tissue injuries and traumatic brain injury. ${ }^{3-6}$ Major studies which evaluated the leucocyte count as a component of scoring systems found that leucocytosis was indicative of increased hospital stay whereas other parameters like hypothermia were predictive of mortality. ${ }^{11,12}$

RDW represents the range of sizes of red blood cells (RBCs). In stressful conditions like trauma, the production of red blood cells was increased. This increased production leads to a difference in sizes of red blood cells being produced, thereby increasing the RDW \% in high-stress states. [8] Also, pro-inflammatory cytokines released as a response to trauma in the body, were known to suppress the erythrocyte maturation, leading to release of larger sized RBCs into circulation and increased RDW \%.13 Majercik et al. in their study, found RDW as a useful marker of chronic health status in trauma patients. A few studies show the association of high RDW \% performed within the first 24 hours with mortality in trauma patients. ${ }^{14}$ Use of RDW as a marker for acute conditions like the trauma is not studied much.

The TLC and RDW \% are simple and easily available tests, performed as a part of complete blood count (CBC). Despite being nonspecific markers of inflammation, we hypothesised that TLC and RDW \% can be used to predict morbidity, in previously healthy patients apparently suffering from minor traumatic injuries. We through this study, assessed the association of the leucocytosis and RDW with morbidity in trauma patients. Our institute being a trauma centre, we studied the correlation of early TLC and RDW done within 24 hours of injury with the morbidity measured in terms of length of hospital stay.

In our study, we observed that the patients with high TLC and RDW turned out to stay longer in the hospital. The most common age group among the subjects was 21 - 30 years. Men were affected more commonly by trauma when compared to women. There is a positive correlation between length of hospital stay and total leucocyte count as well as red cell distribution width. Unlike the common belief that wellnourished patients with high haemoglobin may recover faster, haemoglobin at presentation does not correlate with the length of hospital stay in our study. The correlation of TLC with length of hospital stay was significant whereas the correlation was not significant between RDW and length of hospital stay. 
It is clear in our study that early leucocytosis and RDW help in predicting the increased length of hospital stay.

\section{CONCLUSIONS}

TLC and RDW at presentation can be used as an adjunct in the prediction of higher morbidity along with other significant parameters in trauma patients. TLC and RDW are inexpensive, simple and easily available markers to predict the outcome in trauma. These are particularly important in low-resource settings with heavy trauma burden, like India. Though the correlation of RDW is not statistically significant in this study, it is worth considering planning further larger studies in this aspect.

\section{Limitations}

The baseline pre-trauma RDW and TLC values in the study subjects were not considered. The subjects' chronic health status was analysed using the history gathered, but not through the objectively documented information. The sample size was small to analyse the efficacy of these markers as predictors for morbidity. Further major studies are required to analyse and validate the efficacy of these markers in larger study population.

Data sharing statement provided by the authors is available with the full text of this article at jemds.com.

Financial or other competing interests: None.

Disclosure forms provided by the authors are available with the full text of this article at jemds.com.

\section{REFERENCES}

[1] WHO. Global status report on road safety 2018. Geneva: World Health Organization 2018.

[2] National Crime Records Bureau. Accidental Deaths \& Suicides in India - 2019. New Delhi: National Crime Records Bureau (Ministry of Home Affairs) 2019: p. 120.
[3] Salehi S, Faridaalaee G, Mohammadi N, et al. Correlation of white blood cell count and severity of injury in abdominal trauma; a cross - sectional study. J Med Physiol 2016;1(1):25-30.

[4] Santucci CA, Purcell TB, Mejia C. Leukocytosis as a predictor of severe injury in blunt trauma. West J Emerg Med 2008;9(2):81-5.

[5] Kong T, Park JE, Park YS, et al. Usefulness of serial measurement of the red blood cell distribution width to predict 28-day mortality in patients with trauma. Am J Emerg Med 2017;35(12):1819-27.

[6] Paulus EM, Weinberg JA, Magnotti LJ, et al. Admission red cell distribution width: a novel predictor of massive transfusion after injury. Am Surg 2014;80(7):685-9.

[7] Braun E, Kheir J, Mashiach T, et al. Is elevated red cell distribution width a prognostic predictor in adult patients with community acquired pneumonia? BMC Infect Dis 2014;14(1):129.

[8] Bazick HS, Chang D, Mahadevappa K, et al. Red cell distribution width and all-cause mortality in critically ill patients. Crit Care Med 2011;39(8):1913-21.

[9] Abramson N, Melton B. Leukocytosis: basics of clinical assessment. Am Fam Physician 2000;62(9):2053-60.

[10] Rovlias A, Kotsou S. The blood leukocyte count and its prognostic significance in severe head injury. Surg Neurol 2001;55(4):190-96.

[11] Malone DL, Kuhls D, Napolitano LM, et al. Back to basics: validation of the admission systemic inflammatory response syndrome score in predicting outcome in trauma. J Trauma 2001;51(3):458-63.

[12] Napolitano LM, Ferrer T, McCarter RJ Jr, et al. Systemic inflammatory response syndrome score at admission independently predicts mortality and length of stay in trauma patients. J Trauma 2000;49(4):647-53.

[13] Scharte M, Fink MP. Red blood cell physiology in critical illness. Crit Care Med 2003;31(12 Suppl): S651-7.

[14] Majercik S, Fox J, Knight S, et al. Red cell distribution width is predictive of mortality in trauma patients. J Trauma Acute Care Surg 2013;74(4):1021-6. 